\title{
MIXED DISTANT LEARNING IN PANDEMIC WAVES
}

\author{
Marina Kurbakova \\ Moscow Polytechnic University (Russia)
}

\begin{abstract}
Distance learning is becoming more and more rooted in our life; it will not disappear after the pandemic and occupy a certain large niche in education. Nothing can replace human contact, but we can enhance the remote aspect of learning.
\end{abstract}

In our study, we use the empirical method; data collection by continuous sampling and factual activity. The theoretical research method is reflected in the subsequent modeling of the flexible trajectory in distance education.

The study has found the following results. The alternating phases of distance learning, live lectures and seminars can be planned so that for the period of live communication you need to put the maximum of theory and practice on those issues that are difficult to solve in distance learning.

To build effective work in an online university, an online platform is needed.

When performing the same type of grammar tasks on an online platform with the aim of assimilating them and further automation, the teacher saves energy for more efficient work in the webinar.

The advantages of online learning compared to traditional classes are that an absent student may later be asked to complete a task that will be automatically verified and tracked.

Taking tests and exams in the online conference mode is easier, easier than it seems if you learn to use its convenient options.

The psychophysics of some students is such that the pressure of the teacher in the class is not the best form of assimilation of the material. Having free access to the task, he can complete it at the most favorable time, at the best pace for himself, to remake it.

The disadvantages of the platform are that uncontrolled work on it can lead to an endless search by students for a collective answer to tasks, tasks, based on intuition and their mechanical execution. Do not overestimate the student's desire to comprehend knowledge. Control here should be even more serious than in fulltime classes.

The reasons for teachers' complaints about webinars also occur for the following reasons: there was no temporary opportunity to study and even more confidently use all the features of conference applications, there was no way to connect existing developments in the field of distance and e-learning, and the advantages of mobile applications were not actively used. 
The results of the study can be applied in a new environment in which teachers and educators are not predictably found with the prospect of an inevitable rooting in later life.

Keywords: distance learning; pandemics; webinars; online conferences; online platform

\section{Introduction}

Distance learning is increasingly taking root in our lives; it will not disappear after the pandemic and will occupy a certain, large niche in education. Nothing can replace human contact, and that part of the educational process that remains remote should be turned into the most effective and interesting. The work is devoted to the results of the online format during the spring-autumn semesters of 2020, the search for ways to improve it. The task seems to be especially urgent, since this format tends to develop within the framework of secondary and higher professional education.

The theoretical basis of the article is the research of scientists on this topic, from 2014 to the present time.

The practical significance of the work consists in supplementing and deepening the existing approaches to this format of education, searching for the implementation of ways to make it most effective, to bring it closer to traditional classes to such an extent that the learning process becomes convenient and no less significant for both the teacher and the students.

The purpose of the study is to reflect the observations, advantages, disadvantages, unexpected results of the learning process in 2020, which, due to the circumstances, became the longest, continuous and obligatory for all in the entire history of education, based on the existing knowledge about distance learning.

Reflection of practical results, observations of various practicing specialists in this field are able to form the most acceptable, high-quality method of work in a remote form, corresponding to the present day. Given the rapidly changing environment of this format, the updating of the nature of practical skills and abilities should probably become permanent.

\section{Literature Review}

Distance learning has been successfully used in Europe and United States for a long time; by the time of the pandemic, it was more developed and tested in these countries. The studies of the last 5-8 years show the level and scope of problem solving in this area.

In 2014, an interesting study by Simonson M., Schlosser C. "We Need a Plan - An Instructional Design Approach for Distance Education Courses"1) appeared, which divides distance education and distance learning, two sides of a single educational process: the teacher, for his part, creates a learning model, trying to 
convey it clearly and being specific to the student, who, in turn, participates in the learning process. The study outlines in detail how to make the learning process as effective as possible from an educational, economic and organizational point of view. The article still contains valuable information especially for those educational institutions that create an educational online platform.

In the study by M.K.Keles \& S.A.Ozel "A review of distant learning and learning management systems", the authors note that the separation of the teacher and students is by no means a new concept, and thanks to the development of web technologies this type of education is gaining popularity. This is also due to the fact that this education is the most "flexible", regardless of place and time. Scientists describe the most popular educational management systems (including the Moodle platform, which our university began to use last year), educational tools, and compare them in detail so that it is easy to choose the one well suited for each specific educational institution. Among educational approaches, synchronous and asynchronous methods are especially highlighted, which imply joint and individual lessons on the platform. The authors also make an interesting insight into the history of distance learning ${ }^{2)}$.

Carol A. Chapelle in The Oxford Handbook of Applied Linguistics. ComputerAssisted Language Learning believes that effective language learning on a computer is primarily associated with finding and learning suitable applications. The author devotes most of his research to the search for the psychological nature of language learning: how subconscious it is, and whether such a formulation is possible. The students define it as impossible, which means that the student must pay equal attention to all aspects of the language. The study contains many details of the issue and is a subject of special interest for all teachers of foreign languages ${ }^{3)}$.

The study by Zawacki-Richter O., Buntins K. The position of distance education in a journal network ${ }^{4}$ contains an analysis of the most serious works on distance learning since 2014; the authors define the differences between narrow and wide distance education networks. The study describes the connection with the wider educational technology community and highlights the most prolific contributors to articles on the topic.

Finally, we would like to note the research of the current year by Gokbulut B. "Distant education students' opinion on Distant Education. Enriching Teaching and Learning Environments with Contemporary Technologies"5). It reflects a very important view for the teacher from the other side, the student's one. The students noted the high technical level of work via the Internet and the difficulties of working on online platforms through mobile applications. It was also found that the hardest thing was to update a computer science course - such online courses, as a rule, contain material that students have already taken in regular classes that they know. At the same time, students note the convenience of the absence of time constraints when studying on an online platform. The study also contains opinions on other 
details of the format of online classes, which will be of interest to anyone who teaches remotely.

\section{Materials and methods of research}

In our research, we use the empirical method; collection of data by continuous sampling and factual activity. The theoretical research method is reflected in the subsequent modeling of the flexible trajectory mix of distance education.

The study was conducted at the Moscow Polytechnic University, which has an online Moodle platform, Zoom and Webex applications for conducting special seminars and practical exercises as an additional toolkit.

The observations were carried out daily during scheduled sessions, 6 times a week. The results were recorded throughout the day: if possible, during classes or immediately after them. The experiment began on March 19 and ended on the day of the last exam - June 30; then it was continued in autumn 2020. The research period was preceded by a long stage of creating online content for courses for the online platform Moodle, which is ongoing about a year.

More than 130 undergraduate students of full-time, part-time departments in the specialties "Economics", "Construction", "Electrical Engineering", PR, IT, HR, "Mechanical Engineering", "Biotechnology" in the disciplines "Foreign Language", "English", "Technical English", "Technical Translation" took part.

The data were carefully recorded, then summarized and analyzed. An oral survey was also conducted among students about their impressions of distance learning (in April 2020). About 13\% expressed their dissatisfaction with the training format, saying that this form of work is poorly perceived by them, $18 \%$ approved the format, approximately $30 \%$ were neutral in their assessment, and, accordingly, about $39 \%$ of all students "generally approved this form of training".

\section{Discussion and Results of the Research}

Distance teaching as a matter of work most often at home requires good selfdiscipline and clear organization of work. This topic is not new: it started with freelancing. Like any job, it has its drawbacks, and the main thing here is to clearly plan the day and adhere to this plan. What are the learning variations possible if the teacher's workplace is remote?

The gradation of options has long existed, we find it in studies on distance learning, where 3 main options for distance learning are usually mentioned:

Mixed Model - programs that combine traditional and distance learning with students' independent work.

Web-inhanced Model - traditional, using elements of online learning. It involves classroom lessons of various types with direct contact between the teacher and the student. 
Technology-Mediated Model - e-learning within the framework of distance technologies involves mainly independent study of educational materials on an educational platform.

In this article, we proceed from the experience of using the Technology-Mediated Model, to which we decided to add a certain mix. In short, the formula of learning looks like this:

Work on the online platform + additional tasks attached to the forums of the online platform + an application for conferences (Zoom, Webex and similar) for conducting seminars and certifications.

An online university platform can be of good help in the distant educational process. When performing the same type of grammar tasks on an online platform with the aim of assimilating them and further automating, the teacher saves energy for more efficient work in the webinar, he has more strength and enthusiasm to convey via webinars such knowledge that no online platform will give. Its active use and distance work in general have formed the idea that the alternating phases of distance work and live lectures and seminars can be planned so that during the period of live communication it is necessary to maximize theory and practice on those issues that are difficult to implement in distance learning.

What is the mechanism for creating an online platform if it has not yet been created?

The life cycle of this educational product is as follows. The university administration develops the policy, initiates the strategy of those online courses that it needs.

The departments develop content in accordance with the set guidelines. Then university services help the implementation of this content through its marketing, cost estimation, registration of students and monitoring the control of this course in the learning process.

External control is carried out by experts and external stakeholders: industrial partners, authorities and individuals. Commercial courses can also be created, including for scientific and pedagogical workers of higher education, where programs for improving special and psychological and pedagogical competencies, programs for the methodological support of educational activities, and the formation of skills can be presented. The courses are selected for primary development and implementation, the issue of number of courses in general educational programs and for additional education.

Then the criteria for the selection of courses are formulated: the variability of hours, the presence of a customer, the presence or development of an online-course, models of additional education programs, models of courses are sent to structural units.

The regulatory framework is made up of the "Regulations on online-courses" and "Methodological recommendations for a teacher on the development of an electronic training course." 
Each online course, in its structure, supports various types of educational activities: lectures, video lectures, textographic resources, interactive presentations, virtual workshops, emulators, simulators, banks of test tasks, forums, blogs, webinars and online consultations, as well as automated management of the educational process - electronic record books, journals, summary sheets, curricula, portfolios of students and teachers.

In addition: the online platform is very effective in implementing an individual, flexible educational trajectory. At this stage it is necessary to increase awareness and enhance the academic reputation of the university.

The advantages of this implementation format:

- in each course, a wide variety of types of work can be presented: listening to audio recordings, video materials and assignments to them; work with texts and glossaries, with essays and diagrams (colorful decoration with pictures, diagrams, photographs will help to achieve the maximum effect of perception here); video lectures with teachers-authors of the course and assignments for them; intermediate and final tests that include all of the above practices;

- the possibilities of students in mastering educational programs are expanding: in the field of teaching foreign languages, the advantage of online education is the development of grammatical skills, monotonous accumulation of material on one topic and its automatic verification when the topic has already been explained;

- the implementation of individual educational trajectories is ensured in the best way. A student who has passed the material faster than others can improve his skills, develop others in a more advanced or related online course, while other students pass the main one. At the same time, a lagging student can connect to an online course at any time, a required speed of passing units is set for him (it is usually necessary to reduce it so that enough time is spent on the course to master it).

- increasing the efficiency and quality of education through integration of electronic and traditional forms of education;

- meeting the needs of the employer in obtaining additional competencies by employees.

Target audience of training programs: not only students, but also individuals, enterprises and organizations on a commercial basis, since the necessary educational products can also be created for them.

Types of educational products: programs, courses, individual modules within the main activities of the university; socially oriented programs; center for training and testing in foreign languages, as well as programs for scientific and pedagogical workers, which may include advanced training and foreign language courses.

So, we use the online platform as a convenient system for teaching, first of all, students and automating skills in limited conditions. There are many positive sides here. On average, at least the $2^{\text {nd }}$ year bachelors already determine the tendency to be ready for online education. We mean that the more basic knowledge a person has 
and the more background knowledge as an application to this, the more experience in systematic work, the more he "burns" with the desire to become a highly qualified professional, the more freedom he can be given to use an online -platform, the less he needs to be guided and monitored in a webinar. Such students usually form the basis of any groups. This is the part of students who will complete their studies in any work format.

The main part of a group is intermediate-level students who need guidance within reasonable limits, who, as a rule, want it, and can be provided with a certain space for independent work, including online platforms.

And the last group is students who find it difficult to study in any form of education, who often not steady in high school, they can even study between their retakes. However, we noticed a tendency that the part of them who rarely attended classes not because of poor motivation to study in general, but because of long trips and problems "get up early and reach the university on time" - they study quite willingly remotely, complete all tasks, and sometimes do additional tasks, especially when the teacher allows them to work in the course any time in addition, not only during the hours of the lesson.

The main advantages of online learning in comparison with traditional classes are the following:

1) An absent student does not just skip a lesson, he may later be offered an assignment that was performed in a previous lesson on an online platform, which will be automatically checked and tracked for his performance, moreover, in case of insufficient study (this is indicated by the percentage of correctly completed assignments that appears after completing the task or test), it can be worked out again and again, or a second, third option on this topic is proposed. If the assignment must be checked by a teacher, then it will be done and can be checked much faster, since a personal meeting is not needed here to transfer the assignment. All this suggests that it is with this form of education that the use of a flexible trajectory of the educational process is implemented rather efficiently.

2) It is easier to track their fulfillment of homework, and the process of subsequent submission is much easier, since all the assignments can simply be sent at any time.

3) An obtained practice on the online platform shows (this was also assumed in advance) that uncontrolled work on the platform can lead students to endless searches for a collective answer to a given task, the performance of tasks based on intuition and their mechanical performance. However, in this format the mess can also be prevented by connecting conferencing applications (Webex, Zoom and others of a similar type). A teacher can create each lesson according to the most effective ratio from his point of view - staying with students in Zoom (first of all, for explaining the material, checking knowledge) and working on an online platform. Mostly due to the absence of the latter, the first attempt at total participation in webinars led to massive complaints from teachers, as a result of which not many 
teachers would like to continue teaching in a remote format. Our skepticism here is most likely associated with reluctance to change the established method of work, but if we form the positive attitude, then we become more perfect, more effective from one lesson to another, as it is evidenced by our next observation.

4) It has turned out that taking tests or exams in the zoom is better and easier than it seems at first. A teacher and students do not need to commute, a student instantly finds himself in the place and can also be quickly moved to the waiting room after it, there is no expectation of those who are late - you can do other things and meet them in Zoom later; in other words, in case of necessity, a student can be given additional time for revision and we meet with him later on the same day in order to reduce the number of students who will face retakes. The electronic statement has been created, and it is located specifically in your virtual office - you do not need to fill it out completely or sign it - just put an assessment.

Thus, you can spend as much time as you want on the very process of passing the test/exam and communicating with students; you can increase or decrease it to a minimum if the student's assessment is no doubts in both a positive and a negative sense, and we are confident in the correctness and professionalism of our decision - to turn off the conference when the teacher considers it necessary. The camera records the entire process, and on appeal, it is obvious that the issue was resolved professionally and could not take a long time, in which case you do not remain face to face with the student for endless clarifications how he should be assessed. As we have already mentioned above, a weak student in parallel can complete the necessary, important material to the end and it is even possible reconnecting the videoconference and accepting several of his attempts - this is also not difficult to carry out, while in traditional tests/exams, in this case, it was necessary to be present in the classroom for many hours.

The most successful format of tests/exams, which we tested in 2020, is a oneon-one conversation in the form of questions/ answers on topics previously given to students. The questions formulated by the teacher can be rephrased, during the discussion, clarifying questions can be asked or an attempt to express their opinion on professional topics can be offered - such an approach, due to its spontaneity, is as objective as possible to assess the student's knowledge and confidence that no means are used to help them with the answer. This approach gives a deeper understanding of students' knowledge, the degree of his motivation and what his educational trajectory should be in the future. In other words, this is a communication experience that sometimes cannot always be achieved when students take tests/ exams traditionally and in groups.

One more important detail: some students have such psychophysics that pressure of a teacher at the lesson is not the best form of mastering the material. Having free access to the task, he can complete it at the most favorable time, at the best pace for himself and redo it. And it goes without saying that suggestopedy (Lozanov, 1978) 
and Georgy Lozanov method of teaching (Lozanov \& Gateva, 1988) should be applied as well, taking into consideration that distant learning in 2020 was started in a spontaneous and stressed situation. Here we can rely on positive results of this method's application in project activity of our university.

However, we should not overestimate the student's aspiration to attain knowledge. Control here should be even more serious than in face-to-face classes.

The disadvantages of this type of training are that the student can quietly leave the online platform if the work is not in a webinar. Decision 1: he can return to teaching at another suitable hour, which, as practice shows, students do, and perform everything even better. Decision 2: a teacher can establish the practice of providing a report on the completion of certain tasks at the end of the lesson. In reality, this becomes a practice when some students, including for a good reason, send a report later within a few days, since they completed the task later.

\section{About webinars}

The experience of spring 2020 semester, which was unscheduled online, showed the exhaustion of high school teachers if all classes were 100\% in webinar. We see this for two reasons:

1. There was no time to study and more confidently use all the capabilities of conference applications - sharing virtual board with students, attaching materials to the board and completing assignments on their own, in other words, the built-in teamwork tools were not used, when many participants can work together, use their screens and do tasks, including interactivity.

2. It was not possible to connect the existing developments in the field of distance and e-learning, and its new component at the moment - mobile applications. Now is the time when it might be helpful to remember the benefits of an interactive lesson if this activity was not included in the lesson plan. This can, first of all, include interactions: brainstorming, case-study, problem seminar, building your participation as a teacher in them on the principle of scaffolding, which will be mentioned below. This is especially important, because higher education is called upon to teach independence of thought, the ability to make decisions, this is its primary task.

The essence of the interactive lesson and its advantages can be briefly as follows:

1. Interactive learning is immersed in communication

2. It retains the ultimate goal and the main content of the subject

3. It modifies the forms and techniques of the lesson

All of these educational tools help us to achieve sufficient success in distance learning, making it effective. As we mentioned above, the failure to use this approach significantly burdened distance learning in the first half of 2020 .

So, "an interactive lesson, which must be conducted electronically, is mostly" realized via discussions and seminars through a teleconference, which is carried 
out by a teacher and students. Interactive lessons refer to a simulation method that reflects the current stage in the development of active teaching methodology. It is quite possible to use this method in the classroom in webinars" (Rezaei, 2014).

What forms of interactive assignments are especially suitable for webinars?

Interaction between teachers and students takes place in the form of training. Interactive training via web provides for the participants' encounter with relevant situations that arise in their real professional activities, but are not resolved by standard, traditionally used techniques. To ensure the interactive focus of the training, it is necessary to ask a series of sharp short questions, to which all participants in turn must give answers; suggest a collective task (taken from the game) for 3-5 minutes and finish it with a public presentation; leave any important information for the end of the game lesson; always get feedback from participants" (Heil, Wu, Lee \& Schmidt, 2016).

"The most technically simple form is training in a problematic seminar, which combines brainstorming with a creative approach, where there is room for criticism and questions regarding the problematic situation that is being discussed. In preparation, students search for the necessary information via the Internet.

Discussion at a problem seminar is most effective when it comes down to a discussion of microsituations by all the students. The teacher tries to stimulate participation in the discussion with separate questions, asking each student in a sequence "one by one", inviting each next to present their personal opinion, make a critical remark or ask a question to develop the discussion and direct it on the right track. He coordinates the work so that the students themselves, relying on correct judgments and analyzing the wrong ones, convincingly come to a collective conclusion or generalization.

The case seminar, one more form of interactive lesson, aims to study the technology of situation analysis by understanding it on the basis of the knowledge available or acquired in training. Thus, such training is aimed at developing analytical thinking in the process of identifying a problem, its formulation and solutions. In this case, the situation can be illustrative (summarized), normative, strategic ones. The structure of a case is usually represented by a technological map.

The use of a video case is even more convenient and visual. A proposed video can be fiction or documentary, the author's analysis of the situation and questions for discussion, as well as additional tasks and exercises on the topic. Visualization of a problem situation enhances emotional involvement in the learning process and shifts the emphasis of monotonous learning to mastering skills.

Simulation has common features with both the case-study form and the video case - it is the placement of people in "fictitious, imitating real" situations for the purpose of learning or getting an assessment of the work done, this is learning by action or in action. The scenario of the simulation process is aimed at developing intuition, finding an alternative, non-standard way to solve the problem. The mentor uses scaffolding 


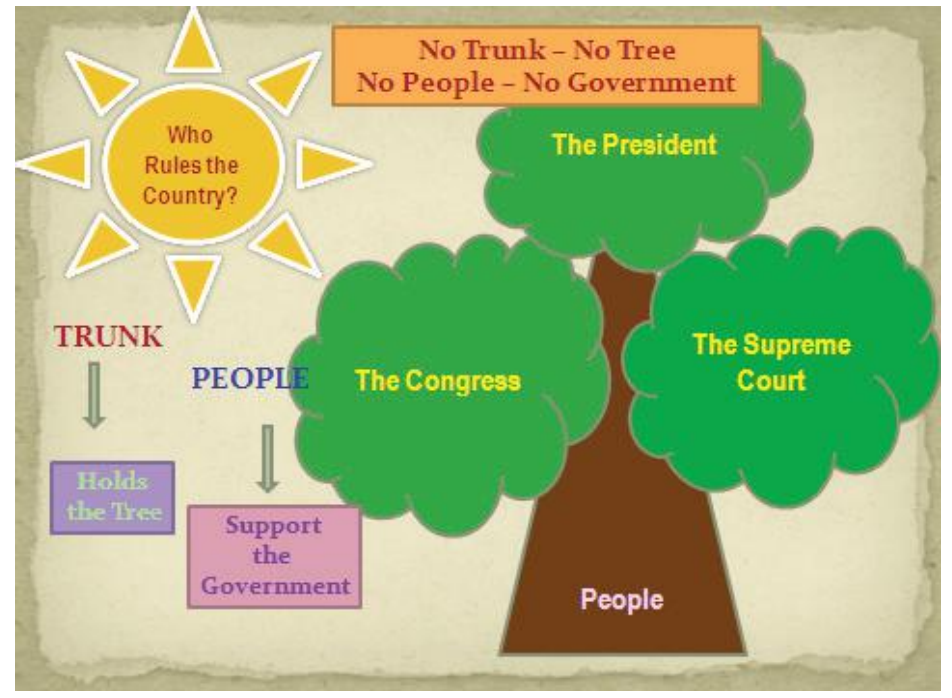

strategy, the main characteristic of which is "fading help" from the teacher during the students' independent work. "Scaffolding" is mentoring (methodological support) from the teacher at the beginning of training can be frequent and meaningful, and by the end of the course is significantly reduced or absent.

Peer learning can be carried out in problem solving situations, content analysis or in specified texts. Students are divided in pairs, and after looking through the text, within 3-5 minutes they must express ideas, discuss controversial points and come to a common opinion. Then the students change the interlocutor, and the discussion begins from the beginning until the formation of a common opinion in this pair. At the end, the teacher listens to each couple's opinion on the analysis of the content, and together they form a common, collective opinion" (Kurbakova \& Kolesnikova, 2020). It is even more expedient to appoint "assessment experts": before the start of the training, the "experts" necessarily announce the assessment criteria that remind the topic of the lesson and the questions to be discussed. Experts announce assessments on a 10-scores scale (for greater accuracy of the assessment), after this each opinion is submitted.

With regard to the use of mobile applications, these tools will especially help us to learn foreign languages in regular classes, outside of them and within the framework of distance learning. Through the mobile application, we can provide our group with the necessary volume of words for preliminary acquaintance in advance, especially since each word in the list is presented in spelling, transcription, sound and picture, and thus thoroughly covers all types of memory that can work when studying. We can also enter into the application, rather than write down a list of necessary words 
in a notebook, which can later be repeated and memorized. And the third of the most common options - after lessons, a teacher drops to the student a list of those words that were taken at classes, which were used for the work and which, as a result, must be memorized. This way of working is described in the article "Using applications in teaching technical English" (Kurbakova \& Kolesnikova, 2020), and the related articles of Indian researchers "Review on Use of Mobile Apps for Language Learning" (Gangaiamaran \& Pasupathi, 2017) and the research "The Effect of Mobile Applications on English Vocabulary Acquisition” (Rezaei, 2014).

\section{Conclusion}

As a result of the study, we came to the following conclusions:

The alternating phases of distance work and live lectures and seminars can be planned in such a way that for the period of live communication it is necessary to maximize theory and practice on those issues that are difficult to solve in distance learning.

To build effective work in an online university, an online platform is needed.

When performing the same type of grammar tasks on an online platform in order to assimilate them and further automate them, a teacher saves energy for more effective work in webinars.

The advantage of online learning over traditional classes is that an absent student can later be asked to complete an assignment, which will be automatically checked and tracked.

Taking tests and exams online is easier than it seems if we learn how to use electronic convenient options.

The psychophysics of a certain part of students is such that the pressure of the teacher in the lesson is not the best form of mastering the material. Having free access to the task, he can complete it at the most favorable time, at the best pace for himself and redo it.

The disadvantages of the platform lie in the fact that uncontrolled work on it can lead to endless searches for a collective answer to tasks, the performance of tasks based on intuition and their mechanical performance. We are do not overestimate the student's aspiration to attain knowledge. Control here should be even more serious than in face-to-face classes.

The reasons for complaints from teachers about distant learning occur for the following reasons: there was no temporary opportunity to study and even more confidently use all the capabilities of conference applications, it was not possible to connect existing developments in the field of distance and e-learning, and the advantages of mobile applications were not actively used.

Developments in interactive have proved their high efficiency more than once, and in this regard, there is a special need to describe, master and include case seminars, web quests, simulations and scaffolding technologies in the framework 
of distance and electronic learning. This allows us to master basic professional competencies in a relaxed mode, enhances emotional involvement in the process, including distance learning, shifts the emphasis from monotony to mastering skills and competencies, creates the effect of mastering oral speech, as it were, "in between things", in the form of a game.

The research results can be applied in the current environment, in which distant learning has strengthened with the prospect of its further spread in our life.

\section{NOTES}

1. Simonson M., Schlosser C. We Need a Plan - An Instructional Design Approach for Distance Education Courses. 2014.

https://www.researchgate.net/publication/237338386_We_Need_a_Plan_An_Instructional_Design_Approach_for_Distance_Education_Courses

2. Keles M.K., Ozel S.A. A review of distant learning and learning management systems. 2016. DOI: 10.5772/65222

https:/www.intechopen.com/books/virtual-learning/a-review-of-distancelearning-and-learning-management-systems

3. Carol A. Chapelle, The Oxford Handbook of Applied Linguistics (2 ed.). Computer-Assisted Language Learning. Edited by Robert B. Kaplan. Oxford University Press. 2017.

4. Zawacki-Richter O., Buntins K. The position of distant education in a journal network. Distance Education 40(1):1-16, 2019. DOI: 10.1080/01587919.2019 $.1692766 \mathrm{https}: / / \mathrm{www}$. researchgate.net/publication/337565447_The position of_Distance_Education_in_a_journal_network

5. Gokbulut B. Distant education students' opinion on Distant Education. Enriching Teaching and Learning Environments With Contemporary Technologies, pp.138-152. 2020. DOI: 10.4018/978-1-7998-3383-3.ch008

https://www.researchgate.net/publication/339118173_Distance_Education_ Students'_Opinions_on_Distance_Education

\section{REFERENCES}

Kurbakova, M.A. (2015). New interactive methods in electronic and distance learning of foreign languages. In: Magiya INNO: novoye $v$ issledovanii yazyka $i$ metodike yego prepodavaniya Materialy Vtoroy nauchno-prakticheskoy konferentsii MGIMO. = Magic INNO: new in the study of language and methods of its teaching Materials of the Second Scientific and Practical Conference of MGIMO. 494 - 500. [In English]

Kurbakova, M.A. (2016). Ways to optimize the process of teaching a foreign language (the modern application of the psychotherapeutic method of 
Dr. Lozanov). In: Yazyk i kultura = Language and culture. No. 3 (35). 137 - 145. [in Russian]

Kurbakova, M.A. \& Kolesnikova, A.A. (2020). Using applications in teaching technical English. In: Yazyk $i$ kul'tura = Language and culture . No. 49.P. 148 - 156. [in English]

Lozanov, G. (1978). Suggestology and outlines of Suggestopedy. Gordon\&Breach Publishing Group. USA.

Lozanov, G. \& Gateva, E. (1988). The Foreign Language Teacher's Suggestopedic Manual. Gordon\&Breach Science Publishers. UK.

Gangaiamaran, R. \& Pasupathi, M. (2017). Review on Use of Mobile Apps for Language Learning. International Journal of Applied Engineering Research. Volume 12, Number 21, Research India Publications. http:// www.ripublication.com

Rezaei, A. (2014). The Effect of Mobile Applications on English Vocabulary Acquisition, Jurnal Teknologi (Science \& Engineering).

Heil, C., Wu, J., Lee, J. \& Schmidt, T. (2016). A Review of Mobile Language Learning Applications: Trends, Challenges, and Opportunities. The EuroCALL Review. 24. 10.4995/eurocall.2016.6402.

Chanier, T. \& Selva T. (1998). The Use of Visual Representations to Enhance Vocabulary Learning. Computer Assisted Language Learning. The ALEXIA System. 